\title{
Retroperitoneal hemorrhage presenting as a vaginal hematoma after a spontaneous vaginal delivery
}

\author{
Adam Baruch, Natalie Clark Stentz*, Sarah M. Wallett
}

Department of Obstetrics and Gynecology, University of Michigan, Ann Arbor, MI, USA

\section{A R T I C L E I N F O}

Article history:

Received 4 December 2014

Received in revised form 6 February 2015

Accepted 14 April 2015

\section{Keywords:}

Interventional radiology

Obstetrics

Retroperitoneal hemorrhage

Vaginal hematoma

Postpartum vaginal hematoma is a rare, painful, and benign event, most commonly due to localized hemorrhage [1]. Rarely, vaginal hematoma can be secondary to a distant, life-threatening hemorrhage. Here, a case of postpartum retroperitoneal hemorrhage presenting as a vaginal hematoma is reported, with successful treatment by arterial embolization.

In July 2013, a patient aged 32 years (gravida 1, para 0) presented to the labor and delivery ward of University of Michigan Hospital and Health Systems (Ann Arbor, MI, USA) with premature rupture of membranes at 38 weeks of pregnancy. At the 35-week prenatal check, thrombocytopenia had been noted (129 000 platelets per $\mu \mathrm{L}$ ) which was resolved to 158000 platelets per $\mu \mathrm{L}$ at the time of admission. On admission, she was 1-cm dilated and $60 \%$ effaced, and the fetal station was -2 . Her labor was augmented with a $10 \mathrm{mg}$ dinoprostone suppository and intravenous oxytocin (30 U per $500 \mathrm{~mL}$ solution titrated per protocol). She progressed to complete dilation and delivered a 2900 -g female neonate over a midline episiotomy after 68 minutes. The episiotomy was repaired with 3-0 Vicryl. The estimated blood loss was $450 \mathrm{~mL}$.

The patient reported rectal pain 3 hours after delivery. Singledigit examination identified a right vaginal sidewall hematoma extending $8 \mathrm{~cm}$ in the cranial-caudal dimension. The patient consented to examination under anesthesia and underwent surgery.

During surgery, palpation of the expanding mass opened the hematoma. Extension was felt superiorly and inferiorly along the right pelvic sidewall. Ultrasonography demonstrated a retroperitoneal hematoma extending $20-30 \mathrm{~cm}$ in the cranial-caudal dimension. Given the extent of the hematoma, a vaginal pack was placed and the patient was transported to the interventional radiology suite after transfusion of two units of packed red blood cells.

Fluoroscopic evaluation did not demonstrate vascular extravasation, perhaps secondary to slowed bleeding rate related to internal compression by blood products expanding within the hematoma. Given high clinical suspicion, the decision was made to embolize the distal branches of the right internal iliac artery with gelatin foam from a left femoral approach. This procedure was completed without complication. The patient received one unit of fresh frozen plasma and one unit of

\footnotetext{
* Corresponding author at: Department of Obstetrics and Gynecology, University of Michigan, 1500 E. Medical Center Drive, SPC 5276, Ann Arbor, MI 48109-5276, USA. Tel.: +1734936 9434; fax: +1 7342326020 .

E-mail address: naclark@med.umich.edu (N.C. Stentz).
}

packed red blood cells before transfer to the labor and delivery ward for recovery.

The next day, the patient returned to the operating room for examination and removal of the vaginal packing. The site of the original hematoma was found to be open and was repaired with a running stitch using 3-0 Vicryl. The patient's postpartum course was otherwise unremarkable. She was advanced to a regular diet, tolerated oral pain medications, and was ambulatory at the time of discharge. She was discharged 2 days after delivery.

Postpartum retroperitoneal hemorrhage is a rare, life-threatening event characterized by bleeding from splanchnic vessels into the retroperitoneal space. Its incidence is speculative because of its rarity [2]. Postpartum retroperitoneal hemorrhage has been associated with traumatic vaginal delivery [3], manual removal of placenta [4], and anticoagulation [5].

Diagnosis of retroperitoneal hemorrhage is often delayed as a result of its rarity and the lack of specific presenting signs and symptoms. Chest, back, and abdominal pain caused by retroperitoneal hemorrhage are often attributed to alternative etiologies [6]. Therefore, a high index of suspicion is necessary to make the correct diagnosis and avoid the associated morbidity and mortality.

Retroperitoneal hemorrhage should be considered as a possible etiology of persistent and localized pelvic, thoracic, back, and epigastric pain associated with a sudden drop in hematocrit. When suspected, ultrasonography is the first diagnostic test. If the suspected hemorrhage is not demonstrated, abdominal computed tomography can effectively demonstrate its presence.

Historically, retroperitoneal hemorrhages were addressed surgically. However, percutaneous arterial embolization has a higher safety index and is a more precise method to address a retroperitoneal hemorrhage in the hemodynamically stable patient [7]. Diagnostic aortography is used to localize the site of bleeding, which is visualized with extravasation of contrast from a traumatized vessel. Once the source of bleeding is located, an embolic agent is injected. Gelatin foam is a commonly used particulate embolization agent [8], and creates a mechanical barrier to continued hemorrhage. Additionally, the cast creates a surface for thrombogenesis. Gelatin foam is a favored embolization agent because of its low cost, ease of use, and many years of clinical use.

Three cases of retroperitoneal hemorrhage following spontaneous vaginal delivery have been reported [2]. The first patient presented with subacute abdominal pain and symptoms of hypovolemic shock due to rupture of the uterine artery 3 days after delivery. The second patient had a retroperitoneal hemorrhage on the second day after delivery secondary to rupture of the right ovarian artery. In the final case, a patient presented with chest pain 1 day after delivery due to rupture of the splenic vein.

The case presented here is unique from these prior cases in two ways. Firstly, the previous cases were addressed surgically, whereas the case presented here was resolved by percutaneous arterial embolization. Notably, arterial embolization was effective, although extravasation from a hemorrhaging vessel was not identified. Secondly, the present patient's retroperitoneal hemorrhage presented as a vaginal hematoma. The prevalence of vaginal hematoma is one in every $300-1500$ deliveries, and the problem most commonly arises following operative delivery or episiotomy [1].

There is ongoing debate as to whether vaginal hematoma should be addressed conservatively or by operative management. On the 
basis of the case presented here, the potential discovery of a retroperitoneal hemorrhage presenting as a vaginal hematoma could favor an operative approach.

In conclusion, a worsening vaginal hematoma in the postpartum setting can be the presenting sign of a retroperitoneal hemorrhage. Percutaneous arterial embolization is an effective method of hemostasis. A high index of suspicion and early diagnosis can be lifesaving.

\section{Conflict of interest}

The authors have no conflicts of interest.

\section{References}

[1] Saleem Z, Rydhström H. Vaginal hematoma during parturition: a population-based study. Acta Obstet Gynecol Scand 2004;83(6):560-2.
[2] Rafi J, Muppala H. Retroperitoneal haematomas in obstetrics: literature review. Arch Gynecol Obstet 2010;281(3):435-41.

[3] Yamashita Y, Torashima M, Harada M, Yamamoto H, Takahashi M. Postpartum extraperitoneal hematoma: imaging findings. AJR Am J Roentgenol 1993;161(4): 805-8.

[4] Rafi J, Muppala H. Conservative management of massive puerperal spontaneous onset retroperitoneal psoas muscle haematoma following normal vaginal delivery. J Obstet Gynaecol 2008;28(1):105-6.

[5] Sherer DM, Dayal AK, Schwartz BM, Oren R, Abulafia O. Extensive spontaneous retroperitoneal haemorrhage: an unusual complication of heparin anticoagulation during pregnancy. J Matern Fetal Med 1999;8(4):196-9.

[6] Gimeno Argente V, Bosquet Sanz M, Ramírez Backhaus M, Trassierra Villa M, Arlandis Guzmán S, Jiménez Cruz JF. Spontaneous retroperitoneal hemorrhage: our experience at last 10 years (in Spanish). Actas Urol Esp 2007;31(5):521-7.

[7] Chan YC, Morales JP, Reidy JF, Taylor PR. Management of spontaneous and iatrogenic retroperitoneal haemorrhage: conservative management, endovascular intervention or open surgery? Int J Clin Pract 2008;62(10):1604-13.

[8] Jain KA, Olcott EW. Magnetic resonance imaging of postpartum pelvic hematomas: early experience in diagnosis and treatment planning. Magn Reson Imaging 1999; 17(7):973-7.

\title{
Polypoid adenocarcinoma of the cervix during pregnancy managed with conservative treatment
}

\author{
Patricia I. Salas, Cristina González-Benitez, Javier De Santiago, Ignacio Zapardiel * \\ Gynecologic Oncology Unit, La Paz University Hospital, Madrid, Spain
}

\section{A R T I C L E I N F O}

\section{Article history:}

Received 8 December 2014

Received in revised form 18 January 2015

Accepted 6 March 2015

\section{Keywords:}

Cancer in pregnancy

Cervical cancer

Fertility-sparing surgery

Simple trachelectomy

Cervical cancer during pregnancy represents an important challenge because of its impact on fetal development, the difficulties in the management of the disease, and the unknown final oncologic outcomes. The main factors to be considered in its management are gestational age, local extension, histological subtype, and lymph node involvement, which seems to be the most important prognostic factor [1].

In August 2012, a woman aged 29 years presented at the Gynecologic Oncology Unit of La Paz University Hospital, Madrid, Spain, after 23 weeks of pregnancy with vaginal bleeding due to a $60-\mathrm{mm}$ polypoid formation in her cervix. The formation was removed surgically, and pathologic analysis showed that it was a poorly differentiated adenocarcinoma of the cervix. Magnetic resonance imaging at 25 weeks of pregnancy showed a residual lesion measuring $16 \times 9 \mathrm{~mm}$, without stromal or parametrial involvement (Fig. 1). The carcinoma was deemed to be International Federation of Gynecology and Obstetrics (FIGO) stage IB2 [2].

\footnotetext{
* Corresponding author at: Gynecologic Oncology Unit, La Paz University Hospital Paseo Castellana 261, 28046 Madrid, Spain. Tel.: + 34 917477008; fax: + 34916325052. E-mail address: ignaciozapardiel@hotmail.com (I. Zapardiel).
}

A simple trachelectomy and a cervical cerclage were performed after 29 weeks of pregnancy. Pathologic assessment revealed a residual well differentiated cervical adenocarcinoma measuring $4 \mathrm{~mm}$ with free surgical margins. At 34 weeks of pregnancy, the cervical cerclage was

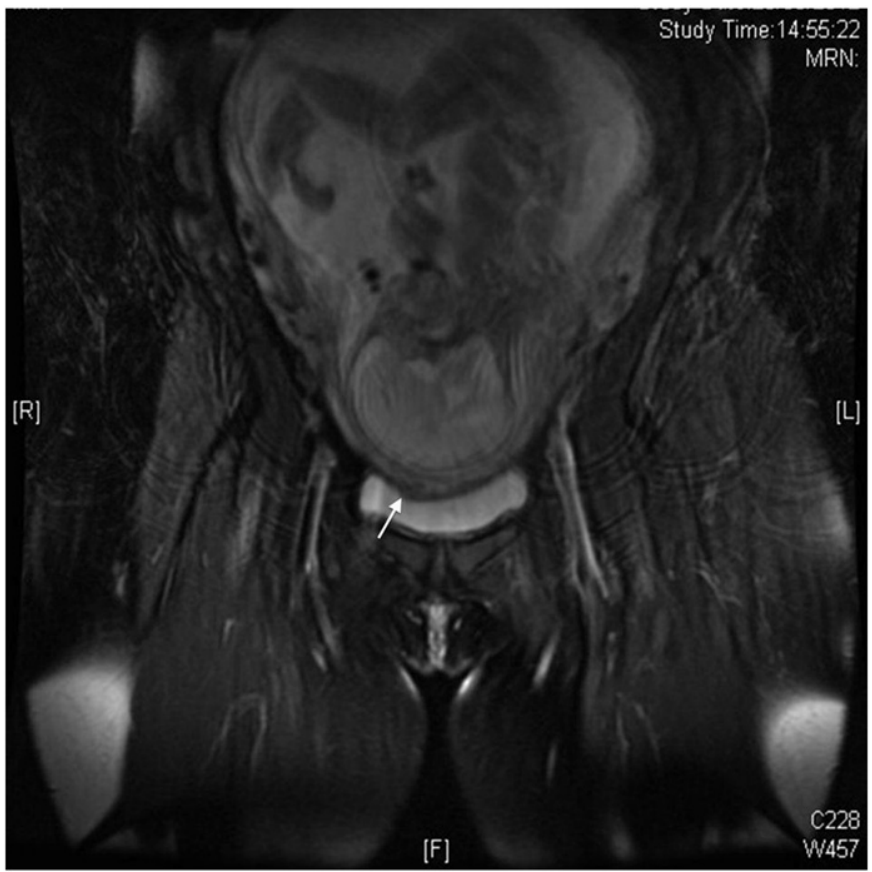

Fig. 1. Magnetic resonance imaging showing a 16-mm cervical lesion (white arrow) in a woman at 25 weeks of pregnancy. 